\title{
Effects of two plant growth-promoting rhizobacteria containing 1-aminocyclopropane-1-carboxylate deaminase on oat growth in petroleum-contaminated soil
}

\author{
J. L. $\mathrm{Liu}^{1} \cdot$ B. M. Xie ${ }^{1} \cdot$ X. H. Shi ${ }^{1} \cdot$ J. M. Ma ${ }^{1}$ C. H. Guo ${ }^{1}$
}

Received: 9 September 2013/Revised: 8 December 2013/Accepted: 14 March 2015/Published online: 9 April 2015

(C) Islamic Azad University (IAU) 2015

\begin{abstract}
Petroleum is potentially toxic to living organisms, and there are worldwide efforts to develop methods for bioremediation of petroleum-contaminated soils. Phytoremediation is an effective method to reduce the concentration of petroleum in soils, and plant growthpromoting rhizobacteria (PGPR) play an important role in the phytoremediation. Two PGPR, Pseudomonas aeruginosa SLC-2 and Serratia marcescens BC-3, were isolated from the rhizophere of Echinochloa grown in petroleumcontaminated soil. These isolates showed capacities for 1-aminocyclopropane-1-carboxylate (ACC) deaminase activity, indole acetic acid production, siderophore synthesis, and the degradation of petroleum. The ACC deaminase activity of SLC-2 and BC-3 was $2.52 \pm 0.03 \mu \mathrm{mol} \alpha$-KA $(\mathrm{mg} \mathrm{Pr} \cdot \mathrm{h})^{-1}$ and $38.52 \pm 0.37 \mu \mathrm{mol} \alpha-\mathrm{KA}(\mathrm{mg} \mathrm{Pr} \cdot \mathrm{h})^{-1}$, respectively. On the other hand, when the concentration of L-Trp increased, the IAA synthesis of BC-3 also increased, while the synthesis of SLC-2 did not change significantly. The ability of synthesized siderophore of SLC-2 was much higher than that of BC-3. The petroleum degradations of SLC-2 and BC-3 increased 4.78 and $7.36 \%$, respectively. The pot experiment of oat was performed to evaluate the plant growth-promoting abilities of SLC-2 and BC-3. Compared with non-inoculated controls, the height and fresh weight of stems increased (23.64 and 42.57) \% and (16.98 and 28.3) \%, respectively, whereas the length and fresh weight of roots also increased (10.34 and 20.84) and (24.13 and 43.11) \%, respectively, when inoculated with
\end{abstract}

C. H. Guo

kaku_2008@163.com

1 Key Laboratory of Molecular and Cytogenetics, Heilongjiang Province, College of Life Science and Technology, Harbin Normal University, Harbin 150025, China
SLC-2 and BC-3. The results indicated that $P$. aeruginosa SLC-2 and $S$. marcescens BC-3 can serve as promising microbes for increasing plant growth in petroleum-contaminated soil to improve the phytoremediation efficiency.

Keywords Plant growth-promoting rhizobacteria (PGPR) - 1-Aminocyclopropane-1-carboxylate (ACC) deaminase $\cdot$ Petroleum $\cdot$ Phytoremediation

\section{Introduction}

With increasing industrialization, environmental problems such as the pollution of the petroleum and saline-alkali fields have become a global issue (Mohawesh et al. 2014; Ogri 2001; Sakai et al. 2004; Sharma et al. 2012). Many developing countries face serious problems with soil pollution, but environmental concerns seem to be a luxury given the economic situation in most countries (Navabakhsh and Tamiz 2013). Common soil cleanup technologies are often beyond financial possibilities, especially if large areas or volumes of soil are contaminated. Furthermore, soil structure and biology can be dramatically disturbed or even destroyed making the land useless for agricultural purposes (Conesa et al. 2014; Merkl et al. 2006). In contrast, phytoremediation, the use of higher plants for decontamination of soil, water, and sediments, is a cost-effective technique that, at the same time, is nondestructive and even has a rehabilitating effect on soil structure and ecology (Marinescu et al. 2010). Phytoremediation, the process of utilizing plants to absorb, accumulate, and detoxify organic pollutants in soil, is considered an alternative strategy for the remediation of soils contaminated with petroleum (Gerhardt et al. 2009; Ma et al. 2009). 
Plant growth-promoting rhizobacteria (PGPR) are beneficial soil bacteria, which may facilitate plant growth and development both directly and indirectly (Lucy et al. 2004), and they can colonize near growing roots, and grow using root exudates as carbon sources. Direct mechanisms include $\mathrm{N}_{2}$ fixation, soil mineral solubilization, productions of plant growth-promoting substances (auxins, cytokinins or gibberellins), and reduction in ethylene levels, among others. Indirect mechanisms include favoring colonization by other beneficial soil microorganisms, as mycorrhizal fungi, and repressing the growth of plant pathogenic microorganisms (Lugtenberg and Kamilova 2009; Vessey 2003), when bacteria decrease or prevent some of the deleterious effects of a phytopathogenic organism by one or more mechanisms. The direct promotion of plant growth by PGPR generally entails providing the plant with a compound that is synthesized by the bacterium or facilitating the uptake of nutrients from the environment (Xie et al. 1996).

There are several ways in which the different PGPR may directly facilitate plant growth: synthesize enzymes that can modulate plant growth and development; synthesize siderophores which can provide iron to plants; and synthesize various phytohormones, such as auxins and cytokinins (Penrose and Glick 2003). A bacterium may promote plant growth using any one way. Moreover, a bacterium may utilize different trains at various times during the life cycle of the plant, providing a mechanism for the solubilization of phosphorus. Soil-plant-microbe interactions are complex, and there are many ways in which the outcome can influence the plant health and productivity (Dastager et al. 2010).

To overcome the disadvantage of phytoremediation in which the growth of plants is inhibited by contaminants, rhizoremediation employing plants and rhizobacteria simultaneously has been recently suggested as a promising strategy. Using the 1-aminocyclopropane-1-carboxylic acid (ACC) deaminase activity, many rhizobacteria can divert ACC. The plant treated with bacteria containing ACC deaminase may have relatively extensive root growth due to less ethylene (Babalola 2010) and can better resist various stresses (Mani and Kumar 2014; Yang et al. 2009). In a recent study, utilization of PGPR which contain ACC deaminase activity, which promotes plant growth and development under both stress and normal conditions, and genetic manipulation of cultivars with genes expressing this enzyme, has attracted much attention among scientists (Sergeeva et al. 2006). Rhizobium leguminosarum bv. trifolii SN10 which could synthesize IAA and ACC deaminase promote the growth of four different rice varieties grown in terms of biomass, root branching, and $\mathrm{N}$ content (Bhattacharjee et al. 2012). Enterobacter cancerogenus MSA2 supplemented with $1 \%$ carboxymethylcellulose showed overall plant growth promotion effect, resulting in enhanced Jatropha cucas root length $124.14 \%$, fresh root mass $81 \%$, fresh shoot mass $120.02 \%$, dry root mass $124 \%$, dry shoot mass $105.54 \%$, number of leaf $30.72 \%$, chlorophyll content $50.41 \%$, and biomass $87.20 \%$ over control under the days of experimental observation (Jha et al. 2012).

The PGPR can increase plant growth by promoting the mineralization of nutrients, the mineral phosphate solubilization, and production of growth hormones like auxin and gibberellins (Hayat et al. 2010; Richardson et al. 2009). Moreover, PGPR are important biological control agents because they can eliminate pathogens from the rhizosphere, the production of beta-1, 3-glucanase, chitinases, antibiotics, hydrogen cyanide, and siderophores, which are composed of low molecular weight iron chelators produced by most bacteria under limiting conditions of this element (Ferreira et al. 2011).

Recently, microbe-assisted phytoremediation has appeared as a more successful approach for the remediation of soil contaminated with petroleum. Therefore, the exploration of new microbial resources, including PGPR, is still necessary for the development of in situ remediation strategies under multifarious conditions. Moreover, a better understanding of the interaction between PGPR and their host plants is important for enhancing the efficiency of microbe-assisted phytoremediation. Therefore, in this study, PGPR, Pseudomonas aeruginosa SLC-2 and Serratia marcescens $\mathrm{BC}-3$, were isolated from the rhizosphere of Echinochloa crusgali growing in petroleum-contaminated soils and then characterized. The plant growthpromoting abilities of the isolates were evaluated, and the effects of inoculation on the growth of oat plants were determined under both petroleum contamination and noncontamination conditions.

\section{Materials and methods}

\section{Isolation of rhizobacteria containing ACC deaminase from petroleum- and salt-contaminated soils}

Rhizobacteria were isolated from the rhizosphere of $E$. crusgali growing in salt- and petroleum-affected soil samples collected form Daqing, China. The method of isolating PGPR entails screening soil bacteria for the ability to use ACC as a sole nitrogen source (Penrose and Glick 2003). The single colony was selected and purified by microbial scribing.

Bacterial strains were revived from $-80{ }^{\circ} \mathrm{C}$ storage and grown on ADF to confirm purity. Single colonies were subcultured to additional LB plates and grown for another 
2 days, after which a loopful of cells was transferred to LB broth and incubated overnight on a rotary shaker $\left(200 \mathrm{rpm}\right.$ at $\left.30^{\circ} \mathrm{C}\right)$. DNA was extracted using the $\mathrm{Ge}-$ nomic DNA Rapid Isolation Kit for Bacterial Cell (BioDev, Beijing). Strains SLC-2 and BC-3 were identified by 16S rDNA analysis. The 16S rDNA sequences of SLC-2 and BC-3 were compared with those present in the GenBank database using a BLAST search (http://www.ncbi. nlm.nih.gov/).

\section{Evaluation of ACC deaminase, IAA production, and siderophore production of the isolated rhizobacteria}

Enzyme assay was done on DF salts supplemented with $0.5 \mathrm{M}$ ACC according to the modified method (Honma and Shimomura 1978) that measures the amount of $\alpha$-ketobutyrate produced when the enzyme cleaves ACC. Total protein was determined by the method of Bradford, using bovine serum albumin as a standard (Bradford 1976).

The production of the indole acetic acid (IAA) by tested bacteria was determined according to the standard methods (Gordon and Weber 1951). Single bacterial colony was inoculated into DF salt minimal medium for 2 days, then $1 \mathrm{~mL}$ aliquot was transferred to different DF salts minimal medium containing L-tryptophan $(0,50,100,200$, and $500 \mu \mathrm{g} / \mathrm{mL}$ ). The cultures were incubated for $48 \mathrm{~h}$ while shaking at $200 \mathrm{rpm}$ at $28^{\circ} \mathrm{C}$.

The production of siderophores by the bacteria was determined according to the standard method (Schwyn and Neilands 1987) using blue agar plates containing the dye chrome azurol S (CAS). Orange halos around the colonies on blue agar were indicative of siderophore excretion.

\section{Bioassay-based plant growth promotion ability in oat}

The plant growth promotion ability of SLC-2 and BC-3 was determined using oat (Avena sativa cv. Baiyan No. 7) in sterile soil under glasshouse conditions. Oat seeds were surface sterilized with $0.5 \%(\mathrm{~V} / \mathrm{V})$ sodium hypochlorite for $10 \mathrm{~min}$ and subsequently washed with sterilized distilled water. For this experiment, pure cultures were grown in TSB at $30{ }^{\circ} \mathrm{C}$ and diluted to a final concentration of $10^{9}$ colony-forming units $(\mathrm{CFU}) / \mathrm{mL}$ in sterile water. The surface sterile seeds were inoculated by immersion in the appropriate SLC-2 and BC-3 suspension $\left(10^{9} \mathrm{CFU}\right)$ for $2 \mathrm{~h}$ on a rotary shaker, air-dried, and sown immediately. Control seeds were treated with sterile distilled water. Fifteen seeds were sown per pot containing $2 \mathrm{~kg}$ of sterile soil (with petroleum concentration of $4.5 \mathrm{~g} / \mathrm{kg}$ dry soil). Thinning of seedlings was done after sowing, and ten seedlings per pot were maintained throughout the experimental period. There were nine pots per treatment, and 30 plants were harvested each harvest period. Morphological characteristics of each plant were recorded: height of stem, fresh weight (FW) of stem, length of root, and FW of root.

\section{Biodegradation of petroleum by isolated rhizobacteria}

The biodegradation assay was carried out in $250 \mathrm{~mL}$ flasks containing $50 \mathrm{~mL}$ mineral medium, containing $1 \mathrm{~g}$ $\mathrm{K}_{2} \mathrm{HPO}_{4}, 0.5 \mathrm{~g} \mathrm{KH}_{2} \mathrm{PO}_{4}, 10 \mathrm{~g} \mathrm{NaCl}, 1.5 \mathrm{~g}\left(\mathrm{NH}_{4}\right)_{2} \mathrm{SO}_{4}$, $0.1 \mathrm{~g} \mathrm{CaCl}_{2}, 0.01 \mathrm{~g} \mathrm{FeSO}_{4} \cdot 7 \mathrm{H}_{2} \mathrm{O}$, and $0.2 \mathrm{~g}$ anhydrous $\mathrm{MgSO}_{4}$ per litter, and containing $50 \mathrm{mg} / \mathrm{L}$ petroleum solution as the sole source of carbon and energy. The inoculums $(10 \% \mathrm{~V} / \mathrm{V})$ contained cells from enrichment cultures.

At the same time, sterile fermentation medium without bacteria was the control. The flasks were shaken $(150 \mathrm{rpm})$ at $30{ }^{\circ} \mathrm{C}$ for 7 days. The collected samples were extracted with petroleum ether and analyzed to check the total petroleum degradation by UV spectrophotometer under $220 \mathrm{~nm}$. The petroleum was used to make the standard curve.

\section{Statistical analyses}

ACC deaminase activity and synthesis of IAA content represented with mean \pm SE. SPSS software was used for growth-promoting results for single-factor analysis of variance (one-way ANOVA).

\section{Results and discussion}

\section{Isolation and identification of bacterial strains containing ACC deaminase}

Strains SLC-2 and BC-3 were isolated from the rhizosphere of the E. crusgali in petroleum and salt-contaminated soil and showed different morphological appearance on ADF medium. They were gram negative. SLC-2 was with a predominance of celadon color and rounded. BC-3 was red colony and rounded.

The bacteria were identified by comparison of the $16 \mathrm{~S}$ rDNA sequences in the NCBI database using BLAST analysis. The closest relatives of strain SLC-2 were found to be $P$. aeruginosa MSSRFV268 (HQ455036.1) with $97 \%$ similarity, and strain BC-3 was found to be Serratia sp. RSPB11 (HE613732.1) with $99 \%$ similarity. According to morphology, physiological, and biochemical characteristics (Table 1) of two strains, SLC-2 was determined as $P$. aeruginosa, and $\mathrm{BC}-3$ as $S$. marcescens. 


\section{Characterization of ACC deaminase, IAA production, and siderophore production}

ACC deaminase that catalyzes degradation of ACC, the immediate precursor of ethylene, into $\alpha$-ketobutyrate and ammonia (Penrose and Glick 2003), which reduces the inhibitory effect of high level of ethylene and plant may build up an improved root system. The presence of ACC deaminase was verified by assaying $\alpha$-ketobutyric acid. The ACC deaminase activity of strain BC-3 was $38.52 \pm 0.37 \mu \mathrm{mol} \alpha-\mathrm{KA}(\mathrm{mg} \mathrm{Pr} \cdot \mathrm{h})^{-1}$, and it was significantly higher than $2.52 \pm 0.03 \mu \mathrm{mol} \alpha-\mathrm{KA}(\mathrm{mg} \mathrm{Pr} \cdot \mathrm{h})^{-1}$ of strain SLC-2 $(P<0.01)$ (Fig. 1). These confirmed that strains SLC-2 and BC-3 produced ACC deaminase. By comparison, $P$. putida UW4, a well-characterized plant growth-promoting bacterium, has an activity level of $2.123 \mu \mathrm{mol} \alpha-\mathrm{KA}$ (mg Pr.h) ${ }^{-1}$ (Ma et al. 2003).

For more than a decade, the stress-induced phytohormone ethylene has been known to inhibit root growth and be responsible for senescence in crop plants and groundnut (Ma et al. 2003; Saravanakumar and Samiyappan 2007). Plant growth-promoting bacteria that contains the enzyme ACC deaminase, when bound to a plant root or to the seed coat of a developing seedling, may act as a mechanism for insuring that the ethylene level within the plant's tissues does not become elevated to the point where root (or shoot) growth is impaired (Saraf et al. 2011). This is in agreement with the findings of Siddikee et al. (2011) who observed a decreased levels of root growth after application of exogenous ethylene or ACC and whom also reported the promotion of root growth following treatment with ethylene inhibitors or antagonists (Zhao and Hasenstein 2009). From the previous findings, it has been established that

Table 1 Physiological and biochemical characteristics of rhizobacteria SLC-2 and BC-3 isolated from the rhizospheric soil of E. crusgali from petroleum-contaminated soil

\begin{tabular}{lll}
\hline Test item & Strain BC-3 & Strain SLC-2 \\
\hline Morphology & rod & rod \\
Gram stain & - & - \\
Flagellum & + & + \\
Catalase & + & + \\
M. R test & - & - \\
V-P test & + & - \\
Hydrolysis of starch & - & - \\
Indole production & - & + \\
Glucose fermentation & + & - \\
Lactose fermentation & - & - \\
Sucrose fermentation & + & - \\
Citrate test & + & + \\
\hline
\end{tabular}

+ means positive; - means negative

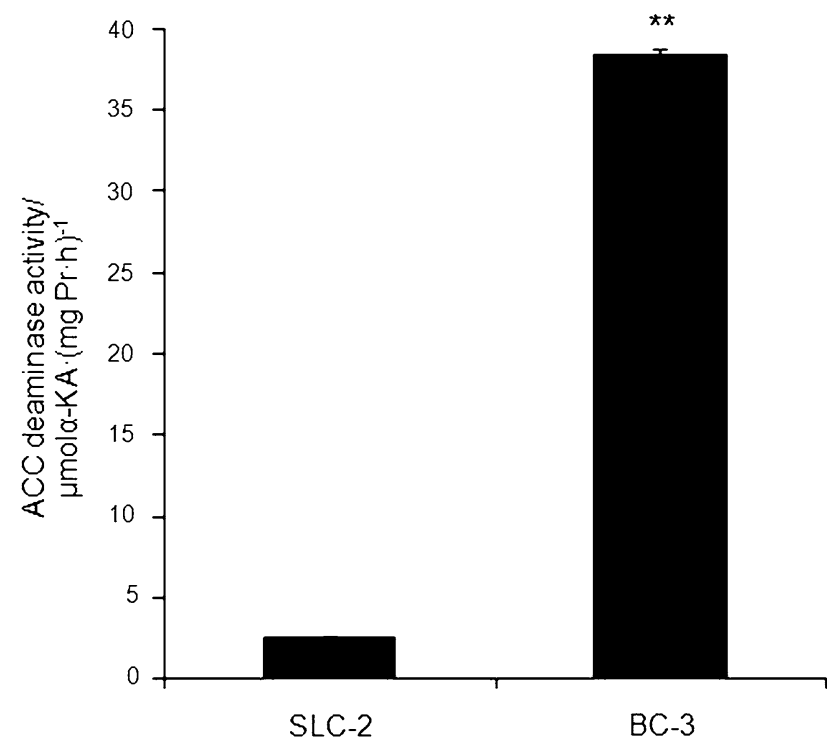

Fig. 1 1-aminocyclopropane-1-carboxylate (ACC) deaminase activity of rhizobacteria SLC-2 and BC-3 isolated from the rhizospheric soil of E. crusgali from petroleum-contaminated soil. Columns represent mean values, and bars represent standard error values $(n=3)$. Double asterisk shows statistic differences $(P<0.01)$

bacteria containing ACC deaminase would act to reduce the level of ethylene and thus confer resistance to various stresses (Glick et al. 1998). At different salinity levels for maize, the Pseudomonas fluorescens containing the ACC deaminase increased the root length and shoot length compared with control (Kausar and Shahzad 2006). Pseudomonas fluorescens strain TDK1 possessing ACC deaminase activity enhanced the yield by reducing the level of stress ethylene when compared with the groundnuts treated with Pseudomonas strains not having ACC deaminase activity (Saravanakumar and Samiyappan 2007).

IAA is the most commonly produced auxin in nature, synthesized mainly through tryptophan-dependent pathways (Tao et al. 2008). The endogenous level of IAA in a plant is also important for successful rooting. The rhizosphere is defined as the zone of soil in which microbes are influenced by the root system and many microbes isolated from the rhizosphere have root growth-stimulating or growth-inhibiting properties. The two isolated rhizobacteria were screened for their ability to produce plant growth regulator IAA, recording with different concentrations of $\mathrm{L}-$ $\operatorname{Trp}(0,50,100,200$, and $500 \mu \mathrm{g} / \mathrm{mL})$ that influence the concentration of it (Fig. 2). The IAA production of the SLC-2 and BC-3 without L-tryptophan was 0.003 and $0.052 \mu \mathrm{g} / \mathrm{mL} \mathrm{OD}_{600}$, and there was a little increase in the production of the auxin in the presence of L-tryptophan. When the media were supplemented with L-tryptophan, the IAA-equivalent synthesis of two isolates increased substantially. Compared with SLC-2, IAA synthesis of BC-3 showed significant differences with different concentrations 


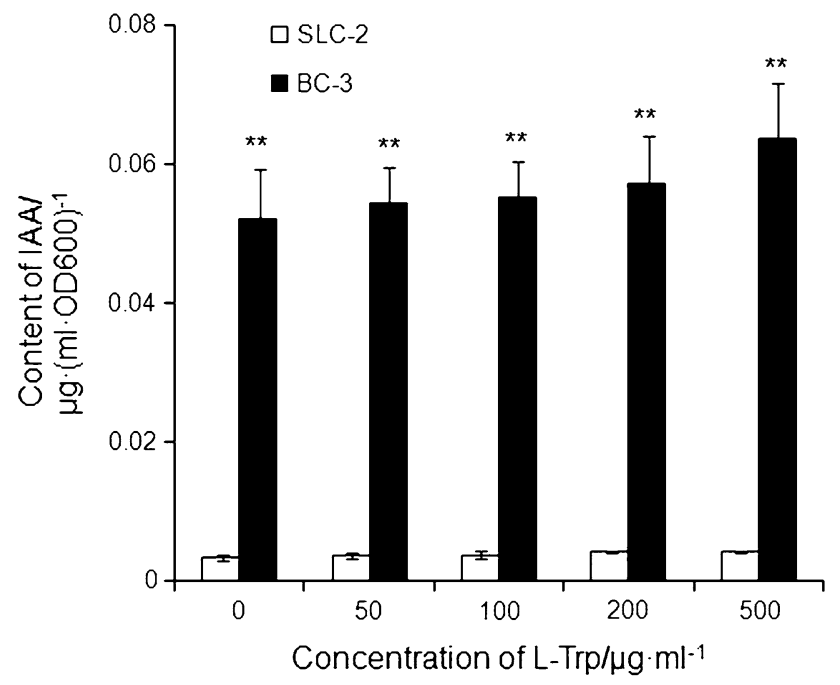

Fig. 2 Indole acetic acid (IAA) synthesis of rhizobacteria SLC-2 and BC-3 isolated from the rhizospheric soil of E. crusgali from petroleum-contaminated soil. Columns represent mean values, and bars represent standard error values $(n=3)$. Double asterisk shows statistic differences $(P<0.01)$

of L-tryptophan $(P<0.01)$. The results of comparison related to different concentrations of L-tryptophan indicate that with increasing L-tryptophan concentrations, the amounts of auxin produced by bacterial strains also increased, which was in agreement with the results of Patten (2002). Similarly, Karnwal (2009) also reported that varying amounts of IAA were produced by Pseudomonads fluorescent. IAA production plays an important role in plant growth and plant-bacteria interactions in metal-contaminated soils (Zaidi et al. 2006).

The siderophores are another important metabolites released by the plant growth-promoting rhizobacteria that indirectly alleviate petroleum toxicity by increasing the supply of iron to the plant. The importance of siderophore production was demonstrated when strains of Pseudomonas putida, which produced siderophores, induced systemic resistance in watermelon against gummy stem rot while the siderophore negative mutants failed to induce resistance (Lee et al. 2001). The yellow halo diameter of SLC-2 was $0.68 \mathrm{~cm}$, and it was longer than BC-3, which was $0.18 \mathrm{~cm}(P<0.01)$. Therefore, the siderophore synthesis by $P$. aeruginosa SLC-2 and S. marcescens BC-3, which were observed in the current study, may have resulted in the measured plant growth (Table 2). According to this study, siderophores produced by these rhizobacteria can help in plant root proliferation and enhancement of soil minerals uptake. Nutrient acquisition has been considered as the primary factor to determine the ecological success of a species at the stressed sites, and the shape has physiological significance in determining the ability of bacterial species to take up the nutrients (Young 2006).
Table 2 Siderophore production by two rhizobacteria SLC-2 and BC-3 isolated from petroleum-contaminated soils

\begin{tabular}{llll}
\hline Rhizobacteria & $\begin{array}{l}\text { Colony } \\
\text { diameter } \\
(\mathrm{cm})\end{array}$ & $\begin{array}{l}\text { Yellow halo } \\
\text { diameter }(\mathrm{cm})\end{array}$ & $\begin{array}{l}\text { Siderophore } \\
\text { production } \\
\text { (yellow halo \%) }\end{array}$ \\
\hline SLC-2 & $0.75 \pm 0.06$ & $0.68 \pm 0.11^{* *}$ & 68 \\
BC-3 & $0.90 \pm 0.08^{*}$ & $0.18 \pm 0.05$ & 18 \\
\hline
\end{tabular}

Mean values \pm standard error values are from three replicates for siderophore production

* Shows statistic difference between experiments $(P<0.05)$, ** shows statistic differences $(P<0.01)$

\section{Bioassay-based plant growth promotion ability in oat}

The plant of oat was inoculated with SLC-2 and BC-3 under petroleum-contaminated conditions in soil cultures to determine the plant growth-promoting abilities of strains. Under contaminated conditions, the inoculation of SLC-2 and BC-3 increased the height of stem, the fresh weight of stem, and the length of root significantly $(P<0.05)$, compared with the non-inoculated control plants (Table 3). Compared with non-inoculated controls, the height and fresh weight of stems increased (23.64 and 42.57) and (16.98 and 28.3) \%, respectively, whereas the length and fresh weight of roots also increased (10.34 and 20.84) and (24.13 and 43.11) \%, respectively, when inoculated with SLC-2 and BC-3.

PGPR could promote the stem to branch and increase the number of the fibrous. The stem height of oat plants inoculated with BC-3 was significant greater than stem height of oat plants inoculated with SLC-2; however, the number of stems of oat plants inoculated with SLC-2 was greater than that of those inoculated with $\mathrm{BC}-3$, therefore, the fresh weight of stems was not significantly different between plants inoculated with SLC-2 and BC-3.

Soil contamination with petroleum is caused by the extraction, transportation, refining, and consumption of petroleum. Remediation of petroleum-contaminated soil is generally a slow and expensive process. Rhizoremediation, employing the interaction of plant roots and rhizobacteria, has been investigated and appears to be costeffective technology for the remediation of contaminated soils (Gerhardt et al. 2009). When PGPR that contain the ACC deaminase bound to a plant root or to the seed coat of a developing seedling may act as a mechanism for insuring that the ethylene level within the plant's tissues does not become elevated to the point where root (or shoot) growth is impaired. Pot trials were carried out on chickpea under $300 \mathrm{mM} \mathrm{NaCl}$ stress, and plant inoculated with Pseudomonas strains MSC1 or MSC4 isolates showed an increase in the parameters that evaluate plant 
Table 3 Effect of SLC-2 and BC-3 inoculation on oat growth in petroleum-contaminated soil

\begin{tabular}{lllll}
\hline & Height of stem $(\mathrm{cm})$ & FW of stem $(\mathrm{g}) / 10$ plants & Length of root $(\mathrm{cm})$ & FW of root $(\mathrm{g}) / 10$ plants \\
\hline Control & $16.16 \pm 0.58 \mathrm{c}$ & $1.06 \pm 0.03 \mathrm{c}$ & $11.61 \pm 0.53 \mathrm{c}$ & $0.58 \pm 0.03 \mathrm{c}$ \\
SLC-2 & $19.98 \pm 0.67 \mathrm{~b}$ & $1.24 \pm 0.03 \mathrm{~b}$ & $12.81 \pm 0.49 \mathrm{~b}$ & $0.72 \pm 0.05 \mathrm{~b}$ \\
BC-3 & $23.04 \pm 0.29 \mathrm{a}$ & $1.36 \pm 0.05 \mathrm{a}$ & $14.03 \pm 0.61 \mathrm{a}$ & $0.83 \pm 0.03 \mathrm{a}$ \\
\hline
\end{tabular}

Mean values \pm standard error values are for height of stem, FW of stem, length of root, and FW of root

$F W$ fresh weight

The different letters show statistic differences between experiments and control $(P<0.05)$

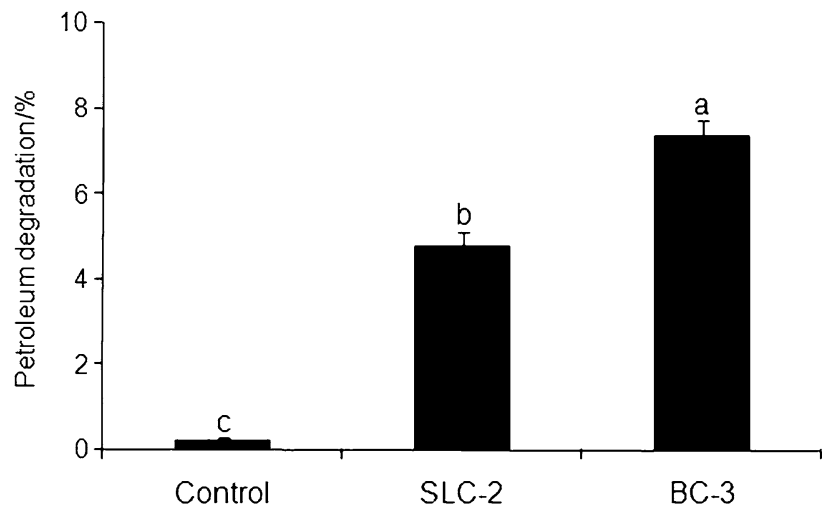

Fig. 3 Petroleum degradation of rhizobacteria SLC-2 and BC-3 isolated from the rhizospheric soil of E. crusgali from petroleumcontaminated soil. Columns represent mean values, and bars represent standard error values $(n=3)$. The different letters show statistic differences between experiments and control $(P<0.01)$

growth when compared to uninoculated controls (Patel et al. 2012). The growth of Zea mays was significantly promoted by the inoculation of the PGPR Gordonia sp. S2RP-17 which contain ACC deaminase in the dieselcontaminated soil (Hong et al. 2011). Plant hormone IAA could increase roots to elongate or improve the development of lateral roots, supplying the plant more nutrition. Siderophores may help the plant absorb more essential element iron, enhancement of soil minerals uptake. Nutrient acquisition is the primary factor to promote the growth of plant. By facilitating the formation of longer roots and shoots, these bacteria may enhance the survival of some seedlings.

\section{Biodegradation of petroleum by isolated rhizobacteria}

The strains SLC-2 and BC-3 not only can promote the growth of plant, but also has the ability to degrade petroleum. The petroleum degradations of SLC-2 and BC-3 were increased 4.78 and $7.36 \%$ compared with control $(P<0.05)$, respectively (Fig. 3). Microbial degradation is the major and ultimate natural mechanism by which one can clean up the petroleum hydrocarbon pollutants from the environment. Bacteria are the most active agents in petroleum degradation, and they work as primary degraders of petroleum in environment (Brooijmans et al. 2009; Rahman et al. 2003). The degradation of these rhizobacteria can reduce the content of the petroleum and lower the organic pollutant stress to the plant, so that the rhizobacteria could promote the growth of the plant (Huang et al. 2004).

Except siderophores, the ACC deaminase, IAA production, the petroleum degradation, and promotion ability of BC-3 were higher than those of SLC-2. The promotion mechanism of strains was not determinate. For further work, we will investigate the promotion mechanism of strains SLC-2 and BC-3 in petroleum-contaminated conditions.

\section{Conclusion}

This work isolated two PGPR strains $P$. aeruginosa SLC-2 and S. marcescens BC-3 from the rhizosphere of Echinochloa crusgalli grown in the petroleum-contaminated soil. The strains SLC-2 and BC-3 were characterized by their plant growth-promoting traits like ACC deaminase activity, IAA, and siderophore production that help plants and may protect them against the contaminant environment. The two rhizobacteria have all the three traits and are higher ACC deaminase, IAA, and siderophore producers, and all of them are petroleum-resistant rhizobacteria related to the soil samples where they were isolated with petroleum concentration. The two isolated PGPR had the ability to degrade the petroleum and could decrease the stress of the petroleum in environment. The oats inoculated with PGPR were higher than in control plants in the petroleum-contaminated soil. Our study suggests that strains SCL-2 and BC-3 could be served as promising microbes to improve the phytoremediation efficiency in petroleum-contaminated soil by increasing plant growth.

Acknowledgments This study was supported by the National Natural Science Foundation of China (Grant No. 31170479), the Natural Science Foundation of Heilongjiang province, China (Grant No. C201142), Programs for Science and Technology Development of Heilongjiang Province, China (Grant No. GC12B304), the Graduate 
Innovation Fund of Harbin Normal University (HSDBSCX2013-04), and Aid program for Science and Technology Innovative Research Team in Higher Educational Institutions of Heilongjiang Province (2010TD10) and Harbin Normal University (KJTD2011-2).

\section{References}

Babalola O (2010) Beneficial bacteria of agricultural importance. Biotechnol Lett 32(11):1559-1570

Bhattacharjee R, Jourand P, Chaintreuil C, Dreyfus B, Singh A, Mukhopadhyay S (2012) Indole acetic acid and ACC deaminaseproducing Rhizobium leguminosarum bv. trifolii SN10 promote rice growth, and in the process undergo colonization and chemotaxis. Biol Fertil Soils 48(2):173-182

Bradford MM (1976) A rapid and sensitive method for the quantitation of microgram quantities of protein utilizing the principle of protein dye binding. Anal Biochem 72:248-254

Brooijmans RJW, Pastink MI, Siezen RJ (2009) Hydrocarbondegrading bacteria: the oil-spill clean-up crew. Microb Biotechnol 2(6):587-594

Conesa HM, María-Cervantes A, Álvarez-Rogel J, González-Alcaraz MN (2014) Role of rhizosphere and soil properties for the phytomanagement of a salt marsh polluted by mining wastes. Int J Environ Sci Technol 11(5):1353-1364

Dastager SG, Deepa CK, Pandey A (2010) Isolation and characterization of novel plant growth promoting Micrococcus sp NII0909 and its interaction with cowpea. Plant Physiol Biochem 48(12):987-992

Ferreira JTP, Santos TMC, Albuquerque LS, Santos JV, Filho JAC, Neto CER (2011) Isolation and selection of growth-promoting bacteria of the genus Bacillus and its effect on two varieties of lettuce (Lactuca sativa L.). Int Res J Microbiol 2(2):70-78

Gerhardt KE, Huang X-D, Glick BR, Greenberg BM (2009) Phytoremediation and rhizoremediation of organic soil contaminants: potential and challenges. Plant Sci 176(1):20-30

Glick BR, Penrose DM, Li J (1998) A model for the lowering of plant ethylene concentrations by plant growth-promoting bacteria. J Theor Biol 190(1):63-68

Gordon SA, Weber RP (1951) Colorimetric estimation of indoleacetic acid. Plant Physiol 26(1):192-195

Hayat R, Ali S, Amara U, Khalid R, Ahmed I (2010) Soil beneficial bacteria and their role in plant growth promotion: a review. Ann Microbiol 60(4):579-598

Hong S, Ryu H, Kim J, Cho K-S (2011) Rhizoremediation of dieselcontaminated soil using the plant growth-promoting rhizobacterium Gordonia sp. S2RP-17. Biodegradation 22(3):593-601

Honma M, Shimomura T (1978) Metabolism of 1-aminocyclopropane-1-carboxylic acid. Agric Biol Chem 42:1825-1831

Huang X-D, El-Alawi Y, Penrose DM, Glick BR, Greenberg BM (2004) Responses of three grass species to creosote during phytoremediation. Environ Pollut 130(3):453-463

Jha C, Patel B, Saraf M (2012) Stimulation of the growth of Jatropha curcas by the plant growth promoting bacterium Enterobacter cancerogenus MSA2. World J Microbiol Biotechnol 28(3): 891-899

Karnwal A (2009) Production of indole acetic acid by Fluorescent Pseudomonas in the presence of L-tryptophan and rice root exudates. J Plant Pathol 91(1):61-63

Kausar R, Shahzad SM (2006) Effect of ACC-deaminase containing rhizobacteria on growth promotion of maize under salinity stress. J Agric Soc Sci 2(4):216-218

Lee YH, Lee WH, Lee DK, Shim HK (2001) Factors relating to induced systemic resistance in watermelon by plant growthpromoting Pseudomonas spp. Plant Pathol J 17(3):174-179
Lucy M, Reed E, Glick BR (2004) Applications of free living plant growth-promoting rhizobacteria. Anton van Leeuw 86(1):1-25

Lugtenberg B, Kamilova F (2009) Plant-growth-promoting rhizobacteria. Annu Rev Microbiol 63(1):541-556

Ma W, Guinel FC, Glick BR (2003) Rhizobium leguminosarum biovar viciae 1-aminocyclopropane-1-carboxylate deaminase promotes nodulation of pea plants. Appl Environ Microbiol 69(8):4396-4402

Ma Y, Rajkumar M, Freitas H (2009) Inoculation of plant growth promoting bacterium Achromobacter xylosoxidans strain Ax10 for the improvement of copper phytoextraction by Brassica juncea. J Environ Manag 90(2):831-837

Mani D, Kumar C (2014) Biotechnological advances in bioremediation of heavy metals contaminated ecosystems: an overview with special reference to phytoremediation. Int $\mathrm{J}$ Environ Sci Technol 11(3):843-872

Marinescu M, Dumitru M, Lăcătuşu A, M Marinescu (2010) The influence of maize and a natural product on the biodegradation of oil polluted soils. Res J Agric Sci 42(3):678-683

Merkl N, Schultze-Kraft R, Arias M (2006) Effect of the tropical grass Brachiaria brizantha (Hochst. ex A. Rich.) Stapf on microbial population and activity in petroleum-contaminated soil. Microbiol Res 161(1):80-91

Mohawesh O, Mahmoud M, Janssen M, Lennartz B (2014) Effect of irrigation with olive mill wastewater on soil hydraulic and solute transport properties. Int J Environ Sci Technol 11(4):927-934

Navabakhsh M, Tamiz R (2013) Influences of rural industries on sustainable social and environmental developments. Int $\mathrm{J}$ Environ Sci Technol 10(1):191-198

Ogri OR (2001) A review of the Nigerian petroleum industry and the associated environmental problems. Environmentalist 21(1): $11-21$

Patel D, Jha C, Tank N, Saraf M (2012) Growth enhancement of chickpea in saline soils using plant growth-promoting rhizobacteria. J Plant Growth Regul 31(1):53-62

Patten CL (2002) Role of Pseudomonas putida indoleacetic acid in development of the host plant root system. Appl Environ Microbiol 68:3795-3801

Penrose DM, Glick BR (2003) Methods for isolating and characterizing ACC deaminase-containing plant growth-promoting rhizobacteria. Physiol Plant 118(1):10-15

Rahman KSM, Rahman TJ, Kourkoutas Y, Petsas I, Marchant R, Banat IM (2003) Enhanced bioremediation of $n$-alkane in petroleum sludge using bacterial consortium amended with rhamnolipid and micronutrients. Bioresour Technol 90(2): $159-168$

Richardson A, Barea J-M, McNeill A, Prigent-Combaret C (2009) Acquisition of phosphorus and nitrogen in the rhizosphere and plant growth promotion by microorganisms. Plant Soil 321(1):305-339

Sakai Y, Matsumoto S, Sadakata M (2004) Alkali soil eeclamation with flue gas desulfurization gypsum in China and assessment of metal content in corn grains. Soil Sediment Contam 13(1):65-80

Saraf M, Jha C, Patel D (2011) The role of ACC deaminase producing PGPR in sustainable agriculture. In: Maheshwari DK (ed) Plant growth and health promoting bacteria microbiology monographs, vol 18. Springer, Berlin, pp 365-385

Saravanakumar D, Samiyappan R (2007) ACC deaminase from Pseudomonas fluorescens mediated saline resistance in groundnut (Arachis hypogea) plants. J Appl Microbiol 102(5): $1283-1292$

Schwyn B, Neilands JB (1987) Universal chemical assay for the detection and determination of siderophores. Anal Biochem 160(1):47-56

Sergeeva E, Shah S, Glick B (2006) Growth of transgenic canola (Brassica napus cv. Westar) expressing a bacterial 
1-aminocyclopropane-1-carboxylate (ACC) deaminase gene on high concentrations of salt. World J Microbiol Biotechnol 22(3):277-282

Sharma NK, Bhardwaj S, Srivastava PK, Thanki YJ, Gadhia PK, Gadhia M (2012) Soil chemical changes resulting from irrigating with petrochemical effluents. Int J Environ Sci Technol 9(2): 361-370

Siddikee MA, Glick BR, Chauhan PS, Wj Yim, Sa T (2011) Enhancement of growth and salt tolerance of red pepper seedlings (Capsicum annuum L.) by regulating stress ethylene synthesis with halotolerant bacteria containing 1-aminocyclopropane-1-carboxylic acid deaminase activity. Plant Physiol Biochem 49(4):427-434

Tao Y, Ferrer J-L, Ljung K, Pojer F, Hong F, Long JA, Li L, Moreno JE, Bowman ME, Ivans LJ, Cheng Y, Lim J, Zhao Y, Ballaré CL, Sandberg G, Noel JP, Chory J (2008) Rapid synthesis of auxin via a new tryptophan-dependent pathway is required for shade avoidance in plants. Cell 133(1):164-176
Vessey JK (2003) Plant growth promoting rhizobacteria as biofertilizers. Plant Soil 255(2):571-586

Xie H, Pasternak JJ, Glick BR (1996) Isolation and characterization of mutants of the plant growth-promoting rhizobacterium Pseudomonas putida GR12-2 that overproduce indoleacetic acid. Curr Microbiol 32(2):67-71

Yang J, Kloepper JW, Ryu C-M (2009) Rhizosphere bacteria help plants tolerate abiotic stress. Trends Plant Sci 14(1):1-4

Young KD (2006) The selective value of bacterial shape. Microbiol Mol Biol Rev 70(3):660-703

Zaidi S, Usmani S, Singh BR, Musarrat J (2006) Significance of Bacillus subtilis strain SJ-101 as a bioinoculant for concurrent plant growth promotion and nickel accumulation in Brassica juncea. Chemosphere 64(6):991-997

Zhao Y, Hasenstein K (2009) Primary root growth regulation: the role of auxin and ethylene antagonists. J Plant Growth Regul 28(4):309-320 